\title{
Perspective on Forensic Odontology and COVID-19
}

\author{
Sachin C Sarode ${ }^{1}$, Jeyaseelan Augustine ${ }^{2}$, Gargi Sarode ${ }^{3}$, Dharmarajan Gopalakrishnan ${ }^{4}$, Shankargouda Patil ${ }^{5}$
}

\begin{abstract}
Novel coronavirus infection (COVID-19) is the most deadly pandemic disease of the century and is now known for its high infectivity, morbidity, and mortality. It is conceivable to expect the ramifications of this pandemic in the form of depression and frustration. An increase in crime rate and violence is expected in the near future. Forensic experts along with forensic odontologists will be receiving many cases shortly and they should be ready to face the challenges. In the present paper, a critical perspective is presented on COVID-19 and its socioeconomic impact. Recommendations are provided for effectively carrying out the investigative procedures related to forensic odontology.

Clinical relevance: Novel coronavirus infection (COVID-19) is the most deadly pandemic disease of the century and is now known for its high infectivity, morbidity, and mortality. Hence, it is recommended to treat every forensic sample as potential COVID-19 infected. In this regard, the present paper gives some important recommendations for handling the samples that are related to forensic odontology. These will prevent the infection spread in the forensic experts, which are considered as the backbone of this critical COVID-19 situation.

Keywords: Coronavirus, COVID-19, Forensic medicine, Forensic odontology.

The Journal of Contemporary Dental Practice (2020): 10.5005/jp-journals-10024-2871
\end{abstract}

\section{INTRODUCTION}

Novel coronavirus infection (COVID-19) is the most deadly pandemic disease of the century and spreading rapidly across the world. ${ }^{1}$ The disease is now known for its high infectivity, morbidity, and mortality. ${ }^{2}$ Vaccines and drug development are in a stage of infancy and might take time to reach out to common people due to mandatory trials. ${ }^{3}$ Hence, social distancing is the only practical solution for tacking the fast-spreading COVID-19. The WHO has recommended nationwide lockdown to facilitate the social distancing strategy, break the chain of infectivity, and decrease the incidence of COVID-19 cases. However, the lockdown has its ramifications and could also have an impact on the field of forensic odontology (FO). In the present paper, a critical perspective is presented on COVID-19 and its socioeconomic impact. Recommendations are provided for effectively carrying out the investigative procedures related to FO.

\section{CoVid-19, Crime Rate, and Forensic EXPERT}

As a measure to put a brake on COVID-19 rapid spread, many countries opted for the strict nationwide lockdown, which also involves the shutdown of local, national, and multinational companies and factories. Moreover, local shops and malls are also closed during the lockdown period. Although this is the best strategic move to control COVID-19, it has resulted in an economic slowdown and unemployment. ${ }^{4}$ The jobless workers in many countries are migrating to their native places. ${ }^{5}$

The world has witnessed an increase in crime rate and violence during the economic recession. The homicide and assault rates were at the peaks during great recession times. ${ }^{6,7}$ The world today is facing a great economic recession due to COVID-19. It is conceivable to expect the ramifications of the pandemic in the form of depression and frustration. ${ }^{8}$ And thus, an increase in crime rate and violence is expected soon.

The increase in crime rate and violence needs skilled manpower for effective management. One of crucial manpower in the $\overline{1,3 \text { Department of Oral Pathology and Microbiology, Dr. DY Patil }}$ Dental College and Hospital, Dr. DY Patil Vidyapeeth, Pimpri, Pune, Maharashtra, India

2Department of Oral Pathology and Forensic Odontology, Maulana Azad Institute of Dental Sciences, Bahadur Shah Zafar Marg, New Delhi, India

${ }^{4}$ Department of Periodontology and Oral Implantology, Dr. DY Patil Dental College and Hospital, Dr. DY Patil Vidyapeeth, Pune, Maharashtra, India

${ }^{5}$ Department of Maxillofacial Surgery and Diagnostic Sciences, Division of Oral Pathology, College of Dentistry, Jazan University, Jazan, Kingdom of Saudi Arabia

Corresponding Author: Sachin C Sarode, Department of Oral Pathology and Microbiology, Dr. DY Patil Dental College and Hospital, Dr. DY Patil Vidyapeeth, Pimpri, Pune, Maharashtra, India, Phone: +91 9922491465, e-mail: drsachinsarode@gmail.com

How to cite this article: Sarode SC, Augustine J, Sarode G, et al. Perspective on Forensic Odontology and COVID-19. J Contemp Dent Pract 2020;21(8):819-821.

Source of support: Nil

Conflict of interest: None

pandemic situation of COVID-19 is the forensic expert. We believe that forensic experts will be receiving many cases shortly and they should be ready to face the challenges. In this tricky situation, we recommend that each forensic expert should treat every case as a potential case of COVID-19 infection. And hence, appropriate guidelines for safety and protection is the need of the hour.

\section{COVID-19 and Forensic Odontology}

The spike receptors of the COVID-19 virus have a strong affinity for the host cell ACE2 protein. ${ }^{9}$ Organs rich in ACE2 receptors are vulnerable for the initiation and progression of the infection. Hence, lungs, gastrointestinal tract, heart, and blood vessels are most commonly affected with morbidity. ${ }^{10}$ Intriguingly, ACE2 receptors 
have been reported at the various locations in the oral cavity. ${ }^{11}$ Thus, the oral cavity is the potential site for causing the infection as well as for spreading the infection. Literature also supports the presence of COVID-19 virus particles in the saliva of the positive patients. ${ }^{12}$

The forensic odontology expert's main job is to collect and analyze the pieces of evidence related to orofacial structures. This commonly includes a wide variety of areas including disaster victim identification, age estimation in both the living and the dead, bite mark investigation, DNA fingerprinting using the oral samples including dental pulp, dentin, and salivary samples, forensic facial reconstruction, and other less-used techniques including rugoscopy, cheiloscopy, and the like. ${ }^{13}$

Disaster victim identification remains the central focus of forensic odontology practice in pandemic times. ${ }^{13}$ India, like many other countries, declared the COVID-19 pandemic as a "notified disaster" in March 2020 and brought it under the ambit of the Disaster Management Act, 2005. Mass casualties have been observed in many parts of the world and humanitarian and dignified management of the dead has been a challenge. ${ }^{14}$ Forensic identification of unidentified dead may utilize forensic odontologists, as dental identification is established as one of the primary identifiers in the identification of the dead. ${ }^{15}$ Mass disasters are rampant throughout this period. Plane crashes, fires at buildings including COVID-19-designated hospitals, and disasters of varied kinds are still rampant. The forensic odontologist must play a major role in identification in these situations which are emergent in nature. Following stringent infection control practices, prevention of crowding, management of kin, and careful collection of evidence is essential. The collection of antemortem records would also require prior disinfection protocols. Guidelines for the digitization of records and electronic transfer of information can prevent cross-infection as well as speed up the process. The need of the hour is for forensic odontologists, even those not involved in the active forensic practice to utilize this opportunity, with most dental practices shut, to sensitize dentists to shift to electronic dental health records as a means to minimize physical contact with infected records. This will greatly enhance the availability of antemortem records and their accessibility which will promote the practice of forensic odontology. Also, the 3D scanning and maintenance of dental casts can save space at the clinic and make records available quickly and remotely. The establishment of these practices requires time and effort, and these periods of lockdown and low volume of patients can be well utilized to develop these systems.

Disaster victim identification largely involves a comparison of antemortem and postmortem records for the identification of victims. ${ }^{13}$ This involves intraoral photography, dental casts, saliva or scrape samples for genetic analysis, etc. ${ }^{14}$ Since COVID-19 could present in the oral cavity, we believe that forensic odontology experts are at high risk of catching the infection. Hence, forensic odontologists should consider every case as a potential positive case of COVID-19. Hence, the formulation of appropriate guidelines is the need of the hour.

Similar guidelines would require to be formulated for bite mark investigation. The recording of impressions, taking of salivary swabs, and dental examination must be done wearing personal protective equipment and with minimal contact. Dental casts and impressions must be disinfected well before use. All suspects and victims must be screened for symptoms of coronavirus disease before entering the healthcare facility. The 3D comparisons of bite marks may be encouraged, using 3D scanning of dentition and bite surfaces, thereby minimizing contact with saliva and surfaces.

The age estimation techniques for most practical purposes involve the use of radiographs. Disinfection of radiology equipment and minimal patient contact would be advisable. The advent of digital methods of radiographic age estimation has eased pressure on infection control practices. ${ }^{16}$ The sections of teeth used for non-radiographic methods may be disinfected using standard protocols before use.

\section{Recommendations and Guidelines for Forensic Odontologists}

- Postmortem sample collection:

- Before collecting the samples, make sure that the whole body is properly disinfected with recommended solutions. The oral cavity is mostly closed and is highly protected due to the dental arch; hence, disinfectants cannot enter inside. Forensic odontologists should make sure that the oral cavity is properly disinfected by putting solutions in the oral cavity.

- A personal protection kit should be mandatory.

- Obtained samples shall be again cleaned with recommended disinfectant solutions.

- Antemortem records: Private dental clinics and dental hospitals are the sources of antemortem records. This involves dental radiographs, dental casts, intraoral photographs, etc. These materials have fewer chances of carrying the COVID-19 virus. However, as precautionary measures, dental casts should be disinfected with recommended disinfectant solutions. All the comparative experiments should be performed by wearing hand gloves, which should be disposed of appropriately.

- DNA sample collection: The protocol for DNA sample collection and transportation has been circulated widely due to the rampant testing for coronavirus by PT-PCR. The standard protocols established countrywide (e.g., Indian Council of Medical Research Guidelines) would be applicable with the sample being sent to the forensic science laboratories in the region.

- Digitalization of all the records must be needed for forensic analysis.

\section{Conclusion}

Looking at the increased mortality and morbidity associated with COVID-19 infection, it is quite conceivable to expect increased burden over the forensic experts including forensic odontology. Potentially every forensic patient or sample could be infected with COVID-19, and hence, utmost precautionary measures need to be taken to prevent the spread of infection. Efforts were made to suggest the recommendations for effective management of samples of odontological importance considering all the possible scenarios. These recommendations are based on the authors' opinion, and hence, they should be critically deliberated by different organizations to formulate the final guidelines that will be applicable across the world.

\section{References}

1. GeH, Wang X, Yuan X, et al. The epidemiology and clinical information about COVID-19. Eur J Clin Microbiol Infect Dis 2020;39(6):1011-1019. DOI: 10.1007/s10096-020-03874-z. 
2. Sun $P, L u X, X u C$, et al. Understanding of COVID-19 based on current evidence. J Med Virol 2020(6). DOI: 10.1002/jmv.25722.

3. Wu SC. Progress and concept for COVID-19 vaccine development. Biotechnol J 2020(6):e2000147. DOI: 10.1002/biot.202000147.

4. Nicola M, Alsafi Z, Sohrabi C, et al. The socio-economic implications of the coronavirus pandemic (COVID-19): a review. Int J Surg 2020;78:185-193. DOI: 10.1016/j.ijsu.2020.04.018.

5. Chakraborty I, Maity P. COVID-19 outbreak: migration, effects on society, global environment and prevention. Sci Total Environ 2020;728:138882. DOI: 10.1016/j.scitotenv.2020.138882.

6. Rosenfeld R. Crime is the problem: homicide, acquisitive crime, and economic conditions. J Quantit Criminol 2009;25(3):287-306. DOI: 10.1007/s10940-009-9067-9.

7. Rosenfeld R, Fornango R. The impact of economic conditions on robbery and property crime: the role of consumer sentiment. Criminol 2007;45(4):735-769. DOI: 10.1111/j.1745-9125.2007. 00096.x.

8. Stein MB. Editorial: COVID-19 and anxiety and depression in 2020. Depress Anxiety 2020;37(4):302. DOI: 10.1002/da.23014.

9. Harapan H, Itoh N, Yufika A, et al. Coronavirus disease 2019 (COVID19): a literature review. J Infect Public Health 2020;13(5):667-673. DOI: 10.1016/j.jiph.2020.03.019.
10. Bourgonje AR, Abdulle $A E$, Timens $W$, et al. Angiotensin-converting enzyme-2 (ACE2), SARS-CoV-2 and pathophysiology of coronavirus disease 2019 (COVID-19). J Pathol 2020. DOI: 10.1002/path.5471.

11. Xu H, Zhong L, Deng J, et al. High expression of ACE2 receptor of 2019nCoV on the epithelial cells of oral mucosa. Int J Oral Sci 2020;12(1):8. DOI: 10.1038/s41368-020-0074-x.

12. Sri Santosh T, Parmar R, Anand $H$, et al. A review of salivary diagnostics and its potential implication in detection of COVID-19. Cureus 2020;12(4):e7708. DOI: 10.7759/cureus.7708.

13. Forrest A. Forensic odontology in DVI: current practice and recent advances. forensic. Sci Res 2019;4(4):316-330. DOI: 10.1080/20961790.2019.1678710.

14. Lake AW, James H, Berketa JW. Disaster victim identification: quality management from an odontology perspective. Forensic Sci Med Pathol 2012;8(2):157-163. DOI: 10.1007/s12024-011-9286-x.

15. Prajapati G, Sarode SC, Sarode GS, et al. Role of forensic odontology in the identification of victims of major mass disasters across the world: a systematic review. PLoS One 2018 13(6):e0199791. DOI: 10.1371/ journal.pone.0199791.

16. Nagi R, Aravinda K, Rakesh N, et al. Digitization in forensic odontology: a paradigm shift in forensic investigations. J Forensic Dent Sci 2019;11(1):5-10. DOI: 10.4103/jfo.jfds_55_19. 